\title{
Evaluation of the Working Time and Remnants on Root Canal Walls after Instrumentation for Removal of Three Different Root Canal Filling Systems
}

Kariem Mostafa Al Batouty

Department of Endodontics, University of Ain shams, Egypt

*Corresponding author: Kariem Mostafa Al Batouty, Department of Endodontics, University of Ain shams, 7 Tayser tour Alanba Pola square Nasr city Cairo Egypt, Tel: +201006090656; E-mail: kbatouty@hotmail.com

Rec date: Mar 04, 2014, Acc date: Apr 09, 2014, Pub date: Apr 11, 2014

Copyright: (c) 2014 Al Batouty KM, et al. This is an open-access article distributed under the terms of the Creative Commons Attribution License, which permits unrestricted use, distribution, and reproduction in any medium, provided the original author and source are credited.

\begin{abstract}
Aim: Evaluation of remaining amount of filling material and working time needed when removing newly introduced glass fiber root canal filling material, Resilon and gutta percha.

Materials and Methods: Sixty roots were randomly divided into three groups $(n=20)$ according to the root canal filling system: Glass fiber group, roots were obturated using glass fiber cones (Stick Tech Ltd, Turku, Finland) and MetaSeal sealer (Parkell Inc, Farmington, NY); Resilon group, Resilon/Epiphany system (Pentron Clinical Technologies, Wallingford, CT); and gutta-percha group, gutta-percha cones and AH Plus (Dentsply, DeTrey, Germany). The obturated canals were retreated by using ProTaper Universal retreatment system (Dentsply Tulsa, Tulsa, OK). The time required to remove the obturation material was recorded using a stop watch. After splitting the roots, the amount of residual filling material on the canal walls was imaged, measured, and calculated as a percentage using the Image J 1.33u Program (National Institutes of Health, Bethesda, MD). Statistical analysis was accomplished using one way ANOVA test. Post hoc Tukey-Kramer multiple comparisons test was used for statistical analysis $(\mathrm{P} \leq 0.05)$.
\end{abstract}

Results: Samples of all groups presented material remnants after retreatment was finished. The group filled with Resilon/Epiphany demonstrated significantly the least percentage of residual filling material $(P<0.05)$. Working Time needed for retreatment was the highest in glass fiber group and the least in Resilon/Epiphany group.

Conclusions: Resilon/Epiphany system is removed from the root canal more efficiently and faster than glass fiber /MetaSeal and gutta percha/AH plus.

Keywords: Glass fiber; Resilon; Gutta-percha; Retreatment

\section{Introduction}

Nonsurgical retreatment requires regaining access to the entire root canal system through complete removal of the core filling material and sealer [1]. Many materials are being used for the filling of root canals, of which gutta-percha is the most common [2,3]. From literature, removal of gutta percha from the root canal did not pose a clinical problem. Many techniques have been advocated for the removal of gutta percha from the root canal. These include rotary files, ultrasonic instruments, heat, and hand files combined with heat or chemicals [4]. Rotary instrumentation has been shown to be more effective than hand files in removing gutta percha from the root canal [5]. Resilon (Pentron Clinical Technologies, Wallingford, CT) is a thermoplastic synthetic polymer-based root canal filling material containing bioactive glass and radiopaque fillers. Previous studies have indicated that Resilon was removed faster and more effectively than gutta percha $[6,7]$.

The concept of using E glass fibers (Stick Tech Ltd, Turku, Finland) to manufacture a core root canal filling material was recently introduced [8]. E glass fibers were used in the manufacturing of fiber posts with its known property of light transmission. Cones made of $\mathrm{E}$ glass fibers were manufactured as a prototype for research purposes (Research laboratory, Biomaterial department, Ain Shams Univeristy,
Cairo, Egypt). This new core root canal filling material was found to provide post endodontic tooth reinforcement to root canal treated teeth [8]. This was explained on the fact that E glass fibers have a dentin-like Young's modulus. This is together with its superior bonding properties to root canal dentine [9]. The sealing ability of glass fiber was studied and it was found that the glass fiber seal the root canal efficiently $[10,11]$. Its ability to transmit light through the root canal and its ease of removal together with its radio-opacity and biocompatibility are still questionable. The purpose of the current study is to evaluate the obturation removal working time and the cleansing thoroughness of canals filled with the newly introduced glass fiber root canal filling material in comparison to Resilon/Epiphany and gutta-percha/AH Plus. The null hypothesis tested in this study was that there was no difference between retreatment of glass fiber with that of Resilon and gutta-percha warm vertical compaction.

\section{Materials and methods}

\section{Sample selection and preparation}

A total of 60 freshly extracted human maxiallry central incisors with single, straight, and completely formed root canals with patent apex, were selected for this study. The dental crowns were removed with a diamond point so that each tooth would have an average length of 15 $\mathrm{mm}$. The working length (WL) was determined visually with a \#15 K- 
Citation: Kariem Mostafa Al Batouty (2014) Evaluation of the Working Time and Remnants on Root Canal Walls after Instrumentation for Removal of Three Different Root Canal Filling Systems. Dentistry 4: 230. doi:10.4172/2161-1122.1000230

Page 2 of 4

file, and $1 \mathrm{~mm}$ was subtracted. After introduction of hand files and establishment of a glide path, all canals were prepared with Revo-S (Micro-Mega, Besanc, on, France) rotary instruments according to the following sequence recommended by the manufacturer: 1) the shaping procedure started in coronal two-thirds of the root canal using SC1 $0.06 \# 25 ; 2$ ) the SC2 $0.04 \# 25$ was inserted to WL; and 3) shaping was continued with SU 0.06 \#25 (universal shaper) to WL, followed by AS $0.06 \# 30$, AS $0.06 \# 35$, and finally, AS $0.06 \# 40$ [12]. Patency of the canals was maintained throughout the procedure by passing a size \#10 K-file approximately $1 \mathrm{~mm}$ through the apex. The canal was irrigated with $2 \mathrm{~mL} 2.5 \%$ sodium hypochlorite solution with a 27 -gauge needle after every instrument. A final rinse with $10 \mathrm{~mL}$ 17\% EDTA (Patterson Dental Supply, Dallas, TX) followed by rinsing with a $10-\mathrm{mL}$ saline solution.

\section{Sample obturation}

The instrumented canals were dried with sterile paper points (Dentsply Tulsa Dental, Johnson City, TN) and randomly divided into three groups $(n=20)$ according to the obturation system. The glass fiber group received the glass fiber cones (Stick Tech Ltd, Turku, Finland) and MetaSeal sealer (Parkell Inc, Farmington, NY). In the Resilon group, root canals were filled with Resilon/Epiphany system (Pentron Clinical Technologies, Wallingford, CT). The roots in the gutta-percha group were filled with gutta-percha cones and AH Plus (Dentsply, DeTrey, Germany). The glass fiber cones were manufactured for the research purpose (Research laboratory, Biomaterial department, Dental School, Ain Shams University, Cairo, Egypt) [9]. All three groups were obturated with a sealing agent (mixed according to the manufacturer's instructions) and a single \#40 0.06 tapered master cone. The prefitted master cone was then coated with the sealer and slowly inserted into the canal to its WL [13]. In glass fiber group, removal of excess material was performed using a round bur and the glass fiber cone was exposed to curing using a light cure device (bluephase C5 ivoclar vivadent) for 180 seconds. Lightcuring was performed for 40 seconds for the Resilon group according to manufacturer's instructions. All samples were sealed with temporary cement and stored at $37^{\circ} \mathrm{C}$ with $100 \%$ humidity for 72 hours.

\section{Retreatment of samples}

A new set of ProTaper retreatment files D1, D2, and D3 were sequentially used until the pre-established WL was reached. Retreatment instruments were activated by an electric engine (XSmart; Dentsply/ Maillefer; $2 \mathrm{~N} / \mathrm{cm}$ torque, 500-rpm speed). No solvent was used in this study [14]. In case the rotary files could not go deeper, stainless steel K-type files were used to achieve the canal patency before reintroducing the rotary instruments. The D1 file was used to remove the coronal filling material, the D2 file was used for the middle, and the D3 file was used for removal of the apical filling material. File penetration was carried out by using light apical pressure. During retreatment, the canals were constantly irrigated with $0.5 \% \mathrm{NaOCl}$. The time required to reach complete retreatment was recorded in seconds with a stopwatch excluding the time for instrument changes and irrigation. The criteria of the completion of retreatment were reaching the WL, smooth canal walls and no evident filling material on the files. After final instrumentation, all canals were copiously irrigated with $\mathrm{NaOCl}$ and dried with paper points. All procedures were performed by the same operator under operating microscope. The canals with separated instruments were excluded from the study, but were recorded and statistically analyzed for frequency of separation using Fisher's exact test.

\section{Evaluation}

Once removal of the root filling material was complete, the teeth were grooved longitudinally on the buccal and lingual surfaces with the steel discs (Brasseler USA, Savannah, GA). They were then split longitudinally with a chisel and a mallet into halves. Both halves were photographed with a digital camera (Nikon Coolpix 885; Nikon, Tokyo, Japan), adapted to a stereomicroscope at $20 \mathrm{X}$ magnification (Global Surgical Corp., St. Louis, MO). The area of the canal and remaining filling material were measured and calculated as a percentage by the Image $\mathrm{J} 1.33 \mathrm{u}$ Program (National Institutes of Health, Bethesda, MD).

\section{Statistical analysis}

The obtained data were collected; tabulated and statistically analyzed. One way ANOVA test was used for comparison between groups, then post hoc Tukey-Kramer multiple comparisons test was used in case of significance. The significance level was set at $\mathrm{P} \leq 0.05$.

\section{Results}

Samples of each group presented material remnants after retreatment was finished. Samples of the glass fiber group showed the highest percentage of remaining root-filling material $(23.9 \pm 1.8)$ (Figure 1) followed by the gutta percha group $(18.0 \pm 2.1)$. The Resilon group showed the lowest percentage of remaining root-filling material $(14.3 \pm 3.5)$. Statistical analysis indicated highly significant differences between tested groups with $(\mathrm{P}$ value $=0.0003)$ (Table 1). There was high significant difference between the glass fiber and Resilon groups $(\mathrm{P}<0.001)$. There was significant difference between the glass fiber and gutta percha groups $(\mathrm{P}<0.05)$.
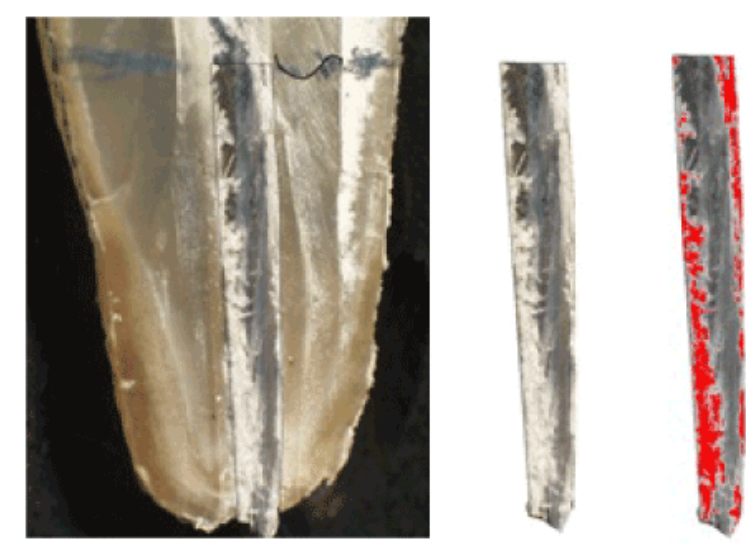

Figure 1: Remaining filling material in a canal obturated with glass fiber core filling material measured and calculated as a percentage by the Image J 1.33u Program

The mean of the working time (seconds) for the retreatment was the highest among the glass fiber group $(104.4 \pm 26.1)$ and the lowest in the Resilon group $(53.0 \pm 14.5)$ (Table 2). There was high significant difference between the three groups $(\mathrm{P}=0.0028)$. There was significant difference between the glass fiber and Resilon groups $(\mathrm{P}<$ 
$0.01)$ and between the glass fiber and gutta percha groups $(\mathrm{P}<0.05)$. Fisher's exact test showed a significant difference between the three groups. There was a higher trend for more separation at the glass fiber group.

\begin{tabular}{|l|l|l|}
\hline Group & Mean \pm S.D. & P-value \\
\hline Glass fiber & $23.9 \mathrm{~b} \pm 1.8$ & \multirow{2}{*}{$0003^{* * *}$} \\
\cline { 1 - 2 } Resilon & $14.3 \mathrm{a} \pm 3.5$ & \\
\cline { 1 - 2 } Gutta percha & $18.0 \mathrm{a} \pm 2.1$ & \\
\cline { 1 - 2 } & &
\end{tabular}

Means with different letters indicate significant difference

Table 1: Remaining Filling Material in the Whole Root Canal (expressed as percentage area) for Each Group

\begin{tabular}{|l|l|l|}
\hline Group & Mean \pm S.D. & P-value \\
\hline $\begin{array}{l}\text { Glass } \\
\text { fiber }\end{array}$ & $104.4 \mathrm{a} \pm 26.1$ & \\
\hline Resilon & $53.0 \mathrm{~b} \pm 14.5$ & \\
\hline GP & $63.0 \mathrm{~b} \pm 14.9$ & \\
\cline { 1 - 1 } Means with different letters indicate significant difference \\
\hline
\end{tabular}

Table 2: Means and Standard Deviations of the Working Time (seconds) for the retreatment

\section{Discussion}

In this study the removal of single cone made from $\mathrm{E}$ glass fibers (Stick Tech Ltd, Turku, Finland) from the root canal was compared to that of Resilon and gutta percha. The results of this study showed that samples of each group presented material remnants after retreatment was finished. This result may be due to the use of file that is smaller than the canal preparation. The taper and size of D3 file, which is the last file in the protaper sequence is 0.07 \# 20. However, the canal was prepared to $0.06 \# 40$. Another reason for such result is absence of use of ultrasonic tips or chloroform. Chloroform was not used in this study, although it effectively dissolves gutta percha and was recommended by the manufacturer for Resilon removal. This is because in the glass fiber group, the E glass fibers did not dissolve by chloroform through a pilot study carried for such purpose. Further investigation is recommended to evaluate the effect of use of the combined use of ultrasonic tips with rotary retreatment instruments on the removal the glass fiber filling material.

The null hypothesis in this study was rejected due to the presence of significant differences between tested groups. The remnants of glass fiber/MetaSeal were more after instrumentation for removal and took a longer time than Resilon and gutta percha groups. A study conducted by Fisher et al. [15] may explain the reason behind the results of the current study on the basis of differences in bond strength among groups. Elbatouty and Hashem [9], found that the glass fiber cones/MetaSeal showed a higher bond strength in comparison to Resilon/Epiphany and gutta percha/AHPlus. They explained this result on the ability of glass fiber cones to transmit light apically, allowing the rapid and complete polymerization of the dual cure resin sealer. The absence of light cure penetration apically in the resilon group resulted in its lower bond strength. Abi Rached et al. stated that
"The lack of photo-activation throughout the specimen extension contributes to its incomplete polymerization, leaving residual monomers in the sealer at the deepest regions of the specimen" [16]. In addition, it has been found that composite resin polymerization is inhibited by the presence of oxygen, and $40 \%$ to $60 \%$ of carbon bonds remain unsaturated [17]. Also, it has been suggested that a low concentration of dimethacrylates or absence of free radicals within Resilon, leading to ineffective coupling with Epiphany, might be the reason for its low bond strength [18]. The fact that glass fiber took longer time than gutta percha and Resilon was due to the high resistance facing the penetration of the protaper files through the $\mathrm{E}$ glass fibers. Perhaps it would have been useful and quicker to use an ultrasonic tip to remove the coronal part which was not the case in the current study [19].

The results of the current study indicated that Resilon/Epiphany system could be removed more effectively compared to the filling made with gutta-percha. This result was also noted in previous studies; for example, Oliveira et al. [6]. Schirrmeister et al. in same year reached the same conclusion [20]. On the other hand, Hassanloo et al. [21] mentioned that there was less filling residue in the gutta-percha/ sealer combination than in the Resilon system after retreatment. Resilon system presented the quickest removal among the groups. The reason behind this may be explained on the basis of the formation of a single block, considering that the Resilon/ Epiphany system will detach from the canal walls as a whole, facilitating its removal as explained by Teixeira et al. [22] The mean times observed for the Resilon and gutta percha groups in the present study, were less than those observed by Cunha et al. [23]. These differences might be explained by the different techniques used for material removal. In addition to the use of shorter roots $(15 \mathrm{~mm})$ in the current study in comparison to those $(17 \mathrm{~mm})$ used in Cunha et al study. Again the mean times in the current study was lesser than that of Somma et al. [24], and this may be explained on the basis that they did not remove the crowns of samples before retreatment.

\section{Conclusions}

Although the removal of the glass fiber cones/ MetaSeal was inferior to Resilon/Epiphany and gutta percha/AH Plus, still it can be removed from the root canal. Single-cone cold obturation techniques do not guarantee the ease of root canal retreatment. Despite the obstacles, the concept of using light transmitting E glass fibers for fabrication of a root canal filling material seems to be promising.

\section{References}

1. 1. Stabholz A, Friedman S (1988) Endodontic retreatment-case selection and technique. Part 2: Treatment planning for retreatment. J Endod 14: 607-614.

2. 2. Kratchman SI (2004) Obturation of the root canal system. Dent Clin North Am 48: 203-215.

3. 3. Whitworth $\mathrm{J}$ (2005) Methods of filling root canals: principles and practices. Endod Topics 12: 2-24.

4. 4. Wilcox LR, Krell KV, Madison S, Rittman B (1987) Endodontic retreatment: evaluation of gutta-percha and sealer removal and canal reinstrumentation. J Endod 13: 453-457.

5. 5. Sae-Lim V, Rajamanickam I, Lim BK, Lee HL (2000) Effectiveness of ProFile. 04 taper rotary instruments in endodontic retreatment. J Endod 26: 100-104.

6. 6. Oliveira DP, Barbizam VB, Trope M, Teixeira FB (2006) Comparison between Gutta-percha and Resilon removal using two different techniques in endodontic retreatment. J Endod 32: 362-364. 
Citation: Kariem Mostafa Al Batouty (2014) Evaluation of the Working Time and Remnants on Root Canal Walls after Instrumentation for Removal of Three Different Root Canal Filling Systems. Dentistry 4: 230. doi:10.4172/2161-1122.1000230

Page 4 of 4

7. 7. Ezzie E, Fleury A, Solomon E, Spears R, He J (2006) Efficacy of retreatment techniques for a resin-based root canal obturation material. J Endod 32: 341-344.

8. 8. Elbatouty KM, Nassif MS (2012) Resistance to fracture and dislodgement of a newly introduced glass fibre root canal filling material versus fibre-reinforced and metal screw posts. ENDO (Lond Engl) 6: 51-57.

9. 9. Elbatouty KM, Hashem AA (2013) Push-out bond strength of a newly introduced glass fiber root canal filling material. J Adhes Dent 15: 161-166.

10. 10. El Batouty KM (2010) Sealing ability of newly introduced glass fiber root canal filling material. 14th international dental congress Cairo, Egypt.

11. 11. El Batouty KM (2010) Its time that light reaches the apical portion of root canal. 16th world congress of dental traumatology, Verona, Italy.

12. 12. Basrani B, Roth K, Sas G, Kishen A, Peters O (2011) Torsional profiles of new and used revo-s rotary instruments: an in vitro study. J Endod 37: 989-992.

13. 13. Fransen J, He J, Glickman G, Rios A, Shulman J, et al. (2008) Comparative assessment of activ gp/glass ionomer sealer, Resilon/ epiphany, and gutta-percha/AH plus obturation: a bacterial leakage study. J Endod 34: 725-727.

14. 14. Huang X, Ling J, Wei X, Gu L (2007) Quantitative evaluation of debris extruded apically by using protaper universal tulsa rotary system in endodontic retreatment. J Endod 33: 1102-1105.

15. 15. Fisher MA, Berzins DW, Bahcall JK (2007) An in vitro comparison of bond strength of various obturation materials to root canal dentin using a push-out test design. J Endod 33: 856-858.

16. 16. Abi Rached J, Gabriel E, Alfredo E, Miranda E, Sousa T, et al. (2009) Bond strength of epiphany sealer prepared with resinous solvent. J Endod 35: 251-255.
17. 17. Franco B, Lopes G, D’alpino H, Pereira C, Mondelli F, et al. (2002) Evaluation of compatibility between different types of adhesives and dual-cured resin cement. J Adhes Dent 4: 271-275.

18. 18. Gesi A, Raffaelli O, Goracci C, Pashley H, Tay R, et al. (2005) Interfacial strength of Resilon and gutta-percha to intraradicular dentin. J Endod 31: 809-813.

19. 19. Wilcox LR (1989) Endodontic retreatment: ultrasonics and chloroform as the final step in reinstrumentation. J Endod 15: 125-128.

20. 20. Schirrmeister JF, Wrbas KT, Meyer KM, Altenburger MJ, Hellwig E (2006) Efficacy of different rotary instruments for gutta-percha removal in root canal retreatment. J Endod 32: 469-472.

21. 21. Hassanloo A, Watson P, Finer Y, Friedman S (2007) Retreatment efficacy of the Epiphany soft resin obturation system. Int Endod J 40: 633-643.

22. 22. Teixeira FB, Teixeira EC, Thompson J, Leinfelder KF, Trope M (2004) Dentinal bonding reaches the root canal system. J Esthet Restor Dent 16: 348-354.

23. 23. Cunh RS, De Martin AS, Barros PP, Da Silva FM, Jacinto RD, et al. (2007) In vitro evaluation of the cleansing working time and analysis of the amount of gutta-percha or Resilon remnants in the root canal walls after instrumentation for endodontic retreatment. J Endod 33: 1426-1428.

24. 24. Somma F, Cammarota G, Plotino G, Grande M, Pameijer C (2008) The effectiveness of manual and mechanical instrumentation for the retreatment of three different root canal filling materials. J Endod 34: 466-469. 